\title{
Pengoptimalan Biaya Transportasi dengan Metoda North West Corner (NWC) dan Stepping Stone (SS) untuk Distribusi Produk Farmasi
}

\author{
Optimization of Transportation Costs with Methode of North West Corner \\ (NWC) and Stepping Stone (SS) for Distribution of Pharmaceutical Products
}

\author{
Tatun Uswatun Hasanah*, Puji Utami, Muchammad Fauzi \\ Jurusan Teknik Industri, Fakultas Teknik, Universitas Widyatama Bandung \\ Jl. Cikutra No.204 A, Sukapada, Cibeunying Kidul, Kota Bandung, Jawa Barat 40125 \\ Email: tatunuswatunhasanah@gmail.com, puji.utami@widyatama.ac.id, muchammad.fauzi@widyatama.ac.id
}

\begin{abstract}
ABSTRAK
Model transportasi diadopsi untuk pengendalian operasi pabrik, penentuan daerah penjualan, pengalokasian lokasi distribusi dan pergudangan. PT. XYZ adalah salah satu perusahaan multinasional yang memiliki core business dibidang industry farmasi. Model optimasi merupakan salah satu model analisis sistem yang diidentikkan dengan operation research. penelitian ini menggunakan Northwest corner method (NWC)untuk memberikan prioritas pengalokasian dari pojok kiri atas matriks transportasi. Stepping Stone Method (SS) merupakan lanjutan dari NWC untuk mendapatkan solusi optimal dengan total biaya terendah. Hasil penelitian menunjukkan bahwa terdapat perbedaan biaya optimal antara perhitungan dengan NWC dan SS. study ini juga membuktikan bahwa dengan menggunakan NWC dan SS, biaya yang didapatkan lebih optimal dibandingkan dengan biaya yang dikeluarkan pada studi kasus ini.
\end{abstract}

Kata Kunci: Model Transportasi, Biaya terendah, Northwest corner (NWC), Stepping Stone Method (SS), Distribusi.

\section{ABSTRACT}

The transportation model was adopted for controlling factory operations, determining sales areas, allocating distribution locations and warehousing. PT. XYZ is a multinational company that has a core business in the pharmaceutical industry. The optimization model is one of the systems analysis models identified by operation research. This research uses Northwest Corner Method (NWC) to give priority allocation from the top left corner of the transportation matrix. Stepping Stone Method (SS) is a continuation of NWC to get the optimal solution with the lowest total cost. The results showed that there were differences in optimal costs between calculations with NWC and SS. This study also proves that by using the NWC and SS, the costs obtained are more optimal than the costs incurred in this case study.

Keywords: Transportation model, lowest cost, Northwest corner method (NWC), Stepping Stone Method (SS), Distribution

\section{Pendahuluan}

Pendistribusian barang atau jasa merupakan suatu proses kegiatan pemasaran yang bertujuan untuk mempermudah kegiatan penyaluran barang dan jasa dari pihak produsen ke pihak konsumen (Fatimah \& Wibawanto,2015). Masalah transportasi merupakan masalah yang sering dihadapi dalam pendistribusian barang (Widya, 2017). Masalah lain yang sering dihadapi terkait distribusi adalah membuat keputusan mengenai rute yang dapat mengoptimakan jarak tempuh atau biaya perjalanan, waktu tempuh, banyaknya kendaraan yang dioperasikan dan sumber daya lain yang tersedia.

Mengoptimalkan jalur dan meminimalkan biaya distribusi, perlu diterapkan suatu model kebijakan pengiriman yaitu dengan optimalisasi jalur pendistribusian barang sehingga dapat memaksimalkan jumlah barang yang dapat diangkut. Optimalisasi distribusi itu dapat dicapai ketika sebuah perusahaan dapat mengirimkan produk dalam kapasitas besar, dengan biaya yang lebih sedikit. Mengirim barang dari satu tempat ke tempat lain memerlukan alat transportasi, baik 
alat transportasi yang dimiliki sendiri maupun menyewa, keduanya memerlukan biaya pengiriman. Tidak kurang dari $60 \%$ dari total biaya logistik perusahaan merupakan biaya transportasi (Zaroni, 2015). Besarnya biaya pengiriman barang dipengaruhi dua variabel, yaitu jumlah barang yang akan dikirimkan dan biaya angkut per unit. (Putri, 2013).

Model transportasi termasuk dalam persoalan program linier. Metode pemrograman linier ini adalah berguna untuk mencari solusisolusi optimal dimana fungi numeriknya terdiri dari satu variable atau lebih yang dihadapkan kepada kendala-kendala (Teguh,2014). Persoalan yang ingin dipecahkan oleh model transportasi adalah penentuan distribusi barang yang akan meminimumkan biaya total distribusi (Permatasari, 2015). Oleh karena itu metode ini tepat untuk menentukan biaya distribusi yang optimal dalam masalah transportasi.

Berdasarkan data managerial distribusi produk farmasi PT. XYZ pada Agustus 2019 yang berlokasi di Jl. Setia Budi Bandung sebagai pelaksana distribusi produk farmasi untuk beberapa wilayah seperti Bogor, Cirebon, Jember, Surabaya, Yogyakarta dan Kuningan. Salah satu strategi yang digunakan menghemat anggaran adalah dengan menekan biaya transportasi seminimal mungkin. Dalam mendistribusikan produk ke berbagai daerah sebagai salah satu bagian dari operasional perusahaan, tentunya membutuhkan biaya transportasi yang tidak sedikit jumlahnya. Untuk itu diperlukan perencanaan yang matang agar biaya transportasi yang dikeluarkan seefisien mungkin dan tidak menjadi persoalan yang dapat menguras biaya besar.

Proses pendistribusian yang tepat sangat penting, maka peneliti ini melakukan evaluasi terhadap saluran distribusi PT.XYZ wilayah Jawa Barat untuk mencari solusi agar biaya distribusi menjadi optimal. Biaya distribusi ini dapat diminimumkan dengan perencanaan pendistribusian produk farmasi secara tepat sehingga biaya distribusi yang dikeluarkan minimum.

NWC (North West Corner Method) merupakan salah satu metode transportasi distribusi yang bisa mengatasi permasalahan pengoptimalan distribusi. Namun kelemahan NWC adalah tidak mempertimbangkan biaya pengiriman pada sel yang bersangkutan (Laely, 2015). Adanya kekurangan pada NWC, maka dioptimalkan lagi dengan SS (Stepping Stone Method) sebagai pembangkit agar biaya cenderung lebih optimal.

\section{Metode Penelitian}

Penelitian ini dilakukan atas beberapa tahap, yaitu tahap studi lapangan, identifikasi masalah dan tujuan, literatur review, pengumpulan data, pengolahan data, analisis, kesimpulan dan saran. Seperti yang digambarkan pada Gambar 1.

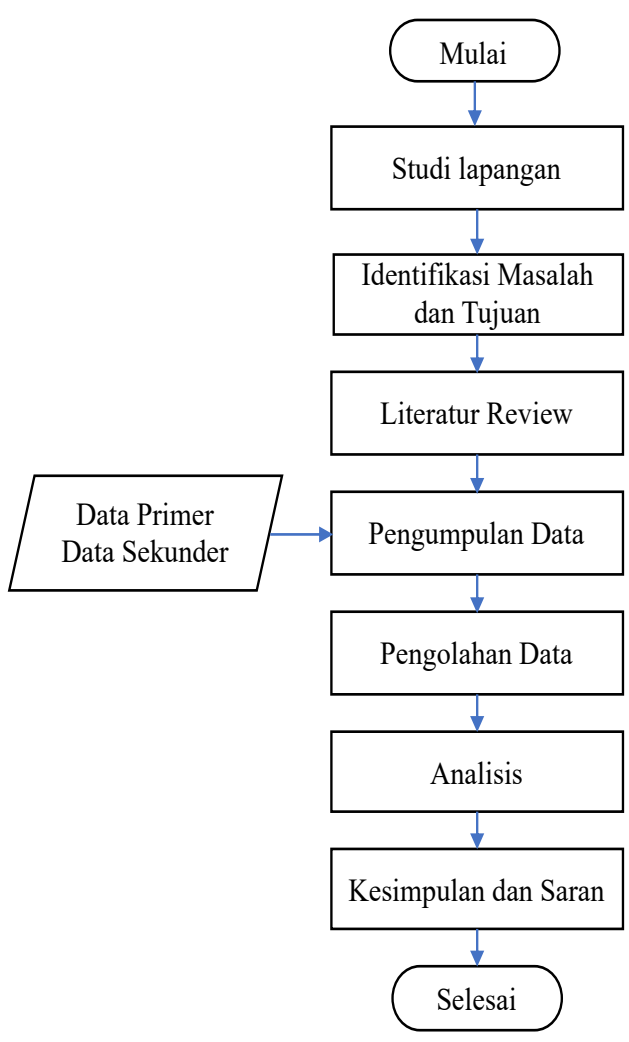

Gambar 1. Alur penelitian

\section{Tahap Identifikasi Masalah, Tujuan, dan Literatur Review}

Pada tahap ini peneliti menentukan tentang topik yang akan diangkat berdasarkan tujuan dari identifikasi masalah di PT.XYZ. Kemudian peneliti melakukan beberapa kajian sesuai dengan topik untuk menyelesaikan masalah distribusi. Kajian fokus pada cara mengoptimalkan pendistribusian produk farmasi ke ritel yang berlokasi di Jawa Barat untuk menghasilkan biaya yang minimum.

\section{Tahap Pengumpulan Data}

Data primer adalah data yang diperoleh secara langsung dari sumber, yaitu data-data hasil wawancara dan diskusi langsung dengan bagian PPIC (Production Planning and Inventory Control) bagian Purchasing dan bagian manajemen IT (Information Technology) di 
PT.XYZ. Data Sekunder merupakan data yang diperoleh secara tidak langsung, yaitu data yang diperoleh dari jurnal dan website yang ada hubungannya dengan penyelesaian masalah.

\section{Tahap Pengolahan Data}

Pada tahap ini dilakukan pengolahan data yang merupaka proses perhitungan secara kuantitatif dengan menggunakan perumusan dengan langkah awal menggunakan metode NWC untuk menentukan solusi fisibel awal :

$$
O T=\sum_{i=1, j=1}^{n} X i j \times C i j
$$

Setelah itu melakukan uji optimalitas dengan menggunakan Metode SS

$$
O T=\sum_{i=1, j=1}^{n} X i j \times C i j
$$

\section{Tahap Analisis}

Pada tahap ini dilakukan analisa data yang merupakan proses identifikasi faktor yang mempengaruhi biaya distribusi produk farmasi. Hasil pengoptimalan biaya distribusi ini dipengaruhi oleh supply, demand dan biaya transportasi.

\section{Hasil dan Pembahasan}

NWC merupakan salah satu metode solusi awal dalam model transportasi dan telah dijelaskan pada pendahuluan. Sebelum menghitung dengan NWC, langkah pertama dimulai dari membuat data kebutuhan produk dengan tabel dibawah ini. Tabel 1 adalah tabel kebutuhan, jumlah stok, dan biaya pengiriman produk farmasi tiap wilayah Jawa Barat, berikut Tabel 1.

Tabel 1. Permintaan produk farmasi di wilayah jawa barat

\begin{tabular}{cccc}
\hline No & Wilayah & Kebutuhan & Satuan \\
\hline 1 & Bandung & 3000 & Box \\
\hline 2 & Bekasi & 2800 & Box \\
\hline 3 & Jakarta & 3000 & Box \\
\hline 4 & Bogor & 1142 & Box \\
\hline 5 & Cirebon & 2397 & Box \\
\hline 6 & Kuningan & 608 & Box \\
\hline 7 & Jember & 1979 & Box \\
\hline 8 & Surabaya & 2567 & Box \\
\hline 9 & Tangerang & 2865 & Box \\
\hline
\end{tabular}

Tabel 2. Jumlah stok produk farmasi di wilayah jawa barat

\begin{tabular}{cccc}
\hline No & Wilayah & Kapasitas & Satuan \\
\hline 1 & Bandung & 5230 & Box \\
\hline 2 & Bekasi & 4350 & Box \\
\hline
\end{tabular}

\begin{tabular}{cccc}
3 & Jakarta & 6450 & Box \\
\hline 4 & Semarang & 2000 & Box \\
\hline 5 & Yogyakarta & 1800 & Box \\
\hline
\end{tabular}

Menurut (Mulyati, 2014) mengenai Perencanaan Tarif Ideal Pengiriman Barang Berdasarkan Metode Perhitungan Biaya Operasional Kendaraan (BOK), pertama penentuan BOK tidak tetap/tahun, kemudian di konversikan menjadi BOK tidak tetap/hari, mencakup kebutuhan mobil truk dan biaya perawatannya, seperti yang ditunjukan pada Tabel 3.

Tabel 3. BOK tidak tetap/tahun

\begin{tabular}{lr}
\hline \multicolumn{1}{c}{ Pengeluaran } & \multicolumn{1}{c}{ Harga } \\
\hline Oli + Filter & $\mathrm{Rp} 2.104 .000$ \\
\hline Ban (luar, dalam) & $\mathrm{Rp} 16.000 .000$ \\
\hline Perawatan dan perbaikan & $\mathrm{Rp} 2.800 .000$ \\
\hline Biaya lain-lain & $\mathrm{Rp} 5.000 .000$ \\
\hline $\begin{array}{l}\text { Jumlah biaya tidak } \\
\text { tetap/tahun }\end{array}$ & $\mathrm{Rp} 25.904 .000$ \\
\hline Jumlah biaya tidak tetap/hari & $\mathrm{Rp} 98.121$ \\
\hline Jumlah biaya tidak tetap/km & $\mathrm{Rp} 1.450$ \\
\hline
\end{tabular}

Kemudian penentuan BOK tetap/tahun, dikonversikan menjadi BOK tetap/hari yang mencakup asuransi kendaraan, gaji supir selama satu tahun, penyusutan kendaraan, biaya uji pemeriksaan KIR yang diasumsikan dilakukan sebanyak 2 kali dalam setahun, seperti Tabel 4.

Tabel 4. BOK tetap/tahun

\begin{tabular}{llr}
\hline \multicolumn{1}{c}{ Pengeluaran } & \multicolumn{2}{c}{ Harga } \\
\hline Penyusutan kendaraan & $\mathrm{Rp}$ & 50.000 .000 \\
\hline Pajak kendaraan & $\mathrm{Rp}$ & 3.000 .000 \\
\hline $\begin{array}{l}\text { Biaya uji pemeriksaan KIR } \\
\text { (2 kali/tahun) }\end{array}$ & $\mathrm{Rp}$ & 600.000 \\
\hline Asuransi kendaraan & $\mathrm{Rp}$ & 10.000 .000 \\
\hline Gaji sopir (12 x Rp1.000.000) & $\mathrm{Rp}$ & 12.000 .000 \\
\hline Jumlah biaya tetap/tahun & $\mathrm{Rp}$ & 75.600 .000 \\
\hline Jumlah biaya tetap/hari & $\mathrm{Rp}$ & 286.364 \\
\hline
\end{tabular}

Jenis truk yang kami gunakan adalah Mitshubishi Colt Diesel FE 7, dengan kapasitas tangki sebesar $70 \mathrm{~L}$, kecepatan yang digunakan sebesar $80 \mathrm{~km} / \mathrm{jam}$, dengan banyaknya bensin jenis solar yang digunakan sebesar $12 \mathrm{~km} / \mathrm{L}$. Jalan truk menggunakan jalan tol jika jalan yang dilalui didukung akes tol. Dari data tabel tersebut dibuat ke dalam bentuk matriks untuk proses perhitungan metode NWC sepertia dalam Tabel 5.

Contoh perhitungan penentuan biaya transportasi dari Bandung ke Bogor, sebagai berikut:

Total Biaya $=$ BOK tidak tetap $/$ hari + BOK tetap/hari + (jarak bandungbogor; harga solar/L) + (jarak 
bandung-bogor $\mathrm{x}$ biaya tidak tetap $/ \mathrm{km}$ )

Total Biaya $=\quad \mathrm{Rp} 98+\mathrm{Rp} 286+(185 \mathrm{~km} ; \mathrm{Rp}$ $9 / \mathrm{L})+(185 \mathrm{kmp} \times 1 / \mathrm{km})$

Total Biaya $=\quad \operatorname{Rp} 798$ (dalam ribuan)

Total Biaya $=\quad$ Rp 798.000

Pada perhitungan BOK tidak tetap/tahun terdapat harga $\mathrm{BOK}$ tidak tetap $/ \mathrm{km}$, merupakan insentif bagi supir dalam pengiriman per $1 \mathrm{~km}$ sebesar $\mathrm{Rp}$ 1.450 yang dikalkulasikan dengan jarak sumber ke tujuan. Dengan satuan kapasitas dan demand seperti yang tercamtum dalam Tabel 1 dan 2 adalah satuan box. Didapat hasil NWC dengan penambahan kolom dummy karena jumlah kapasitas yang lebih besar daripada stok,

Tabel 5. Matriks biaya transportasi dari sumber ke tujuan (dalam ribuan)

\begin{tabular}{|c|c|c|c|c|c|c|c|c|c|c|}
\hline & Bogor & Cirebon & Kuningan & Jember & Surabaya & Tangerang & Bandung & Bekasi & Jakarta & Supplay \\
\hline \multirow{2}{*}{ Bandung } & 798 & 867 & 702 & 2511 & 2124 & 782 & 428 & 684 & 724 & \multirow[b]{2}{*}{5230} \\
\hline & & & & & & & & & & \\
\hline \multirow{2}{*}{ Bekasi } & 518 & 842 & 896 & 2475 & 2100 & 505 & 684 & 445 & 434 & \multirow[b]{2}{*}{4350} \\
\hline & & & & & & & & & & \\
\hline \multirow{2}{*}{ Jakarta } & 512 & 874 & 929 & 2517 & 2131 & 467 & 724 & 434 & 397 & \multirow[b]{2}{*}{6450} \\
\hline & & & & & & & & & & \\
\hline \multirow{2}{*}{ Semarang } & 144 & 905 & 918 & 1548 & 1108 & 1427 & 1372 & 1329 & 1376 & \multirow[b]{2}{*}{2000} \\
\hline & & & & & & & & & & \\
\hline \multirow{2}{*}{ Yogyakarta } & 171 & 1171 & 1182 & 1494 & 1108 & 1693 & 1631 & 1595 & 1637 & \multirow{3}{*}{1800} \\
\hline & & & & & & & & & & \\
\hline Demand & 1142 & 2397 & 608 & 1979 & 2567 & 2865 & 3000 & 2800 & 3000 & \\
\hline
\end{tabular}

Tabel 6. Hasil matriks transportasi NWC (dalam ribuan)

\begin{tabular}{|c|c|c|c|c|c|c|c|c|c|c|}
\hline & $\frac{\text { Bogor }}{\text { (D1) }}$ & $\frac{\text { Cirebon }}{\text { (D2) }}$ & $\begin{array}{c}\text { Kuningan } \\
\text { (D3) }\end{array}$ & $\begin{array}{c}\text { Jember } \\
\text { (D4) }\end{array}$ & $\frac{\text { Surabaya }}{\text { (D5) }}$ & $\begin{array}{c}\text { Tangerang } \\
\text { (D6) }\end{array}$ & $\frac{\text { Bandung }}{\text { (D7) }}$ & $\frac{\text { Bekasi }}{\text { (D8) }}$ & $\begin{array}{c}\text { Jakarta } \\
\text { (D9) }\end{array}$ & Supply \\
\hline Bandung & 798 & 867 & 702 & 2511 & 2124 & 782 & 428 & 684 & 724 & 5230 \\
\hline$(\mathrm{S} 1)$ & 1142 & 82397 & 608 & 1083 & & & & & & \\
\hline Bekasi & 518 & 842 & 896 & 2475 & 2100 & 505 & 684 & 445 & 434 & 4350 \\
\hline (S2) & & & & 896 & 2567 & 887 & & & & \\
\hline Jakarta & 512 & 874 & 929 & 2517 & 2131 & 467 & 724 & 434 & 397 & 6450 \\
\hline (S3) & & & & & & 1978 & 3000 & 1472 & & \\
\hline Semarang & 1443 & 905 & 918 & 1548 & 1108 & 1427 & 1372 & 1329 & 1376 & 2000 \\
\hline (S4) & & & & & & & & 1328 & 672 & \\
\hline Yogyakarta & 1709 & 1171 & 1182 & 1494 & 1108 & 1693 & 1631 & 1595 & 1637 & 1800 \\
\hline (S5) & & & & & & & & & 1800 & \\
\hline Dummy & 0 & 0 & 0 & 0 & 0 & 0 & 0 & 0 & 0 & 528 \\
\hline (SDummy) & & & & & & & & & 528 & \\
\hline Demand & 1142 & 2397 & 608 & 1979 & 2567 & 2865 & 3000 & 2800 & 3000 & \\
\hline
\end{tabular}

Biaya total yang didapatkan dari metode NWC. Kemudian dilakukan pengoptimalan kembali hasil total biaya yang lebih murah lagi, berikut matriks iterasi pertama metode Stepping Stone.

Total biaya distribusi PT.XYZ di wilayah Jawa Barat dengan metode Stepping Stone sebagai berikut,

$O T=\sum_{i=1, j=1}^{n} X i j x C i j$

$$
O T=
$$$$
(\operatorname{Rp} 867 \times 1622)+(\operatorname{Rp} 702 x 608)+(\operatorname{Rp} 428 \times 300
$$

$0)+$

$(\operatorname{Rp} 518 x 1142)+(\operatorname{Rp} 842 \times 775)+(\operatorname{Rp} 2.475 \times 218)$

$+$

$(\mathrm{Rp} 445 x 2215)+(\operatorname{Rp} 467 x 2865)+(\operatorname{Rp} 434 \times 585)$ $+$

$(\mathrm{Rp} 397 \times 3000)+(\mathrm{Rp} 1.108 \times 2000)+(\mathrm{Rp} 1.494 \times 1$

$233)+(1108 \times 567)+(\operatorname{Rp} 0 \times 528)$

$O T=\operatorname{Rp} 13.341 .654$ (dalam ribuan)

$O T=\operatorname{Rp} 13.341 .654 .000$ 
Tabel 7 Hasil matriks iterasi ke-1 transportasi stepping stone (dalam ribuan)

\begin{tabular}{|c|c|c|c|c|c|c|c|c|c|c|}
\hline & $\frac{\text { Bogor }}{\text { (D1) }}$ & $\frac{\text { Cirebon }}{\text { (D2) }}$ & $\frac{\text { Kuningan }}{\text { (D3) }}$ & $\frac{\text { Jember }}{\text { (D4) }}$ & $\frac{\text { Surabaya }}{\text { (D5) }}$ & $\begin{array}{c}\text { Tangerang } \\
\text { (D6) }\end{array}$ & $\begin{array}{c}\text { Bandung } \\
\text { (D7) }\end{array}$ & $\frac{\text { Bekasi }}{\text { (D8) }}$ & $\frac{\text { Jakarta }}{\text { (D9) }}$ & Supply \\
\hline Bandung & 798 & 867 & 702 & 2511 & 2124 & 782 & 428 & 684 & 724 & 5230 \\
\hline$(\mathrm{S} 1)$ & 1142 & 2397 & 608 & 1083 & & & & & & \\
\hline Bekasi & 518 & 842 & 896 & 2475 & 2100 & 505 & 684 & 445 & 434 & 4350 \\
\hline$(\mathrm{S} 2)$ & & & & 896 & 1239 & 2215 & & & & \\
\hline Jakarta & 512 & 874 & 929 & 2517 & 2131 & 467 & 724 & 434 & 397 & 6450 \\
\hline (S3) & & & & & & 650 & 3000 & 2800 & & \\
\hline Semarang & 1443 & 905 & 918 & 1548 & 1108 & 1427 & 1372 & 1329 & 1376 & 2000 \\
\hline (S4) & & & & & & & & & 2000 & \\
\hline Yogyakarta & 1709 & 1171 & 1182 & 1494 & 1108 & 1693 & 1631 & 1595 & 1637 & 1800 \\
\hline (S5) & & & & & 1328 & & & & 472 & \\
\hline Dummy & 0 & 0 & 0 & 0 & 0 & 0 & 0 & 0 & 0 & 528 \\
\hline (SDummy) & & & & & & & & & 528 & \\
\hline Demand & 1142 & 2397 & 608 & 1979 & 2567 & 2865 & 3000 & 2800 & 3000 & \\
\hline
\end{tabular}

Tabel 8. Hasil matriks iterasi ke-12 transportasi stepping stone (dalam ribuan)

\begin{tabular}{|c|c|c|c|c|c|c|c|c|c|c|}
\hline & $\begin{array}{c}\text { Bogor } \\
\text { (D1) }\end{array}$ & $\begin{array}{c}\text { Cirebon } \\
\text { (D2) }\end{array}$ & $\begin{array}{c}\text { Kuningan } \\
\text { (D3) }\end{array}$ & $\begin{array}{c}\text { Jember } \\
\text { (D4) }\end{array}$ & $\begin{array}{c}\text { Surabaya } \\
\text { (D5) }\end{array}$ & $\begin{array}{c}\text { Tangerang } \\
\text { (D6) }\end{array}$ & $\begin{array}{c}\text { Bandung } \\
\text { (D7) }\end{array}$ & $\begin{array}{c}\text { Bekasi } \\
\text { (D8) }\end{array}$ & $\frac{\text { Jakarta }}{\text { (D9) }}$ & Supply \\
\hline Bandung & 798 & 867 & 702 & 2511 & 2124 & 782 & 428 & 684 & 724 & 5230 \\
\hline (S1) & & 1622 & 608 & & & & 3000 & & & \\
\hline Bekasi & 518 & 842 & 896 & 2475 & 2100 & 505 & 684 & 445 & 434 & 4350 \\
\hline (S2) & 1142 & 775 & & 218 & & & & 2215 & & \\
\hline Jakarta & 512 & 873 & 929 & 2517 & 2131 & 467 & 724 & 434 & 397 & 6450 \\
\hline (S3) & & & & & & 2865 & & 585 & 3000 & \\
\hline Semarang & 1443 & 905 & 918 & 1548 & 1108 & 1427 & 1372 & 1329 & 1376 & 2000 \\
\hline (S4) & & & & & 2000 & & & & & \\
\hline Yogyakarta & 1709 & 1171 & 1182 & 1494 & 1108 & 1693 & 1631 & 1595 & 1637 & 1800 \\
\hline (S5) & & & & 1233 & 567 & & & & & \\
\hline Dummy & 0 & 0 & 0 & 0 & 0 & 0 & 0 & 0 & 0 & 528 \\
\hline (Sdummy) & & & & 528 & & & & & & \\
\hline Demand & 1142 & 2397 & 608 & 1979 & 2567 & 2865 & 3000 & 2800 & 3000 & \\
\hline
\end{tabular}

\section{Kesimpulan}

Pendistribusian produk farmasi di PT. XYZ dengan menggunakan metode transportasi didapatkan hasil yang optimal. Total biaya transportasi untuk solusi awal dengan menggunakan metode NWC Rp21.394.461.000 dan uji optimal menggunakan metode Stepping Stone didapatkan hasil yang optimal Rp13.341.654.000. Dalam mendapatkan biaya yang optimal dapat digunakan metode lain agar dalam hal ini lebih bisa mengetahui metode yang lebih baik dalam mengoptimalkan biaya pendistribusian.

\section{Ucapan Terima Kasih}

Jurnal ini tidak akan rampung tanpa keterlibatan orang-orang yang sudah membantu kami menyusun jurnal ini, kami ucapkan terimakasih sebesar-besarnya kepada:
1. Orang tua kami yang senantiasa mendo'akan yang terbaik bagi kami dalam menyusun jurnal ini.

2. Dosen pembimbing kami, Bapak Fauzi yang sudah membimbing kami selama menyusun jurnal ini.

3. Rekan-rekan sekelas yang sudah menjadi penyemangat kami dalam menyusun jurnal ini.

\section{Daftar Pustaka}

Fatimah, N. L., \& Wibawanto, H., (2015). Implementasi Pengoptimalan Biaya Transportasi dengan North West Corner Method (NWCM) dan Stepping Stone Method (SSM) untuk Distribusi Raskin pada Perum Bulog Sub Drive Semarang, Jurnal Ede Komputika. pp. 48-54. 
Laely, N. (2015). Implementasi Pengoptimalan Biaya Transportasi dengan NWC Methode dan Stepping Stone Method untuk Distribusi Raskin pada Perum Bulog Sub Drive Semarang, Universitas Negeri Semarang.

Mulyati, E., and Aghitsna, A.,I.(2014). Perencanaan Tarif Ideal Pengiriman Barang Berdasarkan Metode Perhitungan Biaya Operasional Kendaraan (BOK), Politeknik Pos Indonesia.

Permatasari, D,. (2015)., Optimasi Distribusi Gula Merah pada UD Sari Bumi Raya Menggunakan Model Transportasi, Universitas Dian Nuswantoro, Semarang.

Putri, N.,(2013), Aplikasi Metode Stepping-Stone untuk Optimasi Perencanaan Biaya pada Suatu Proyek Konstruksi, Universitas Sam Ratulangi, Manado.

Teguh, M. (2014), Matematika Ekonomi, Jakarta.

Widya, I.,(2017). Mengoptimalkan Distribusi Pakan Ternak dengan Menggunakan Metode Transportasi, Universitas Maarif Hasyim Latif. Zaroni., Transportasi dalam Rantai Pasok dan Logistik, Supply Chain Indonesia, 2015. 